\title{
MÜLLER CELL-DERIVED NEUROTROPHIC FACTORS. A ROAD TO NEUROPROTECTIVE THERAPY IN THE RETINA
}

\author{
FACTORES NEUROTRÓFICOS DERIVADOS DE LAS CÉLULAS \\ DE MÜLLER. EN EL CAMINO HACIA LA TERAPIA \\ NEUROPROTECTORA EN LA RETINA
}

\author{
HAUCK SM ${ }^{1}$, UEFFING $\mathrm{M}^{2}$
}

En un grupo de degeneraciones retinianas heredadas como la Retinitis Pigmentosa (RP) y la Degeneración Macular Asociada a la Edad (DMAE), la protección de fotorreceptores contra la degeneración puede considerarse como el objetivo clave de las estrategias terapéuticas del futuro. De forma similar, en otro grupo de enfermedades causantes de ceguera que produce muerte de las células ganglionares retinianas (neuropatías ópticas glaucomatosas), la protección de estas neuronas contra la degeneración es igualmente crucial. A pesar de la diversidad de mutaciones que producen susceptibilidad o causan degeneración, el evento unificador que conduce a la ceguera es la apoptosis de las neuronas retinales. Este proceso fatal ha dado lugar a estudios intensivos sobre la naturaleza y los mecanismos moleculares de los agentes neuroprotectores que pueden antagonizar la apoptosis.

El factor neurotrófico derivado de una línea celular glial (GDNF, siglas en inglés) ha demostrado ser uno de los agentes neurotróficos más efectivos para rescatar a los fotorreceptores de la degeneración en el modelo de ratón rdl de RP (1). Sin embargo, hemos demostrado recientemente que el GDNF no actúa directamente sobre los fotorreceptores moribundos de la retina afectada. Específicamente, el GDNF activa las células gliales retinales de Müller (RMG) que a su vez liberan moléculas que soportan la supervivencia de los fotorreceptores (2).

Este hallazgo añade una dimensión adicional a la multiplicidad de funciones de las células gliales de Müller en el contexto de la salud y la enfermedad reti- niana. Es sabido que las células de Müller proporcionan agua y homeostasis iónica al tejido retinal, entregan glutamato neurotransmisor reciclado, protegen las neuronas contra el estrés oxidativo y segregan sustancias vasoactivas, neuroactivas y neuroprotectoras (3). Por otra parte, su morfología les permite actuar como «fibras ópticas» que transmiten la luz desde la membrana limitante interna a través de la totalidad del grosor de la retina hasta los segmentos externos fotosensibles de los fotorreceptores (4). Esta plétora de mecanismos moleculares, fundamentales para un mantenimiento y funcionamiento correcto de la retina, resalta la importancia de las células de Müller en las patologías retinianas. De hecho, cada patología retinal se expresa con una cierta reactividad de las células de Müller, que puede complicar o compensar el proceso patológico molecular.

Puesto que las células de Müller son fuentes intrínsecas de proteínas neuroprotectoras, soportan la supervivencia prolongada de las neuronas retinales. Sin embargo, se ha observado que la secreción de dichos factores neuroprotectores puede perderse en determinadas patologías que acompañan la gliosis reactiva de las células de Müller. Por otra parte, resaltar el soporte neuroprotector en las patologías retinales neurodegenerativas podría ser eficiente para prolongar la supervivencia de las neuronas retinales durante periodos prolongados de tiempo en la vida de los pacientes. Un requisito previo para esta estrategia es la identificación de las proteínas neuroprotectoras derivadas de las células de Müller. Actualmente, se están aplicando abordajes genómi-

\footnotetext{
Research Scientist, Dr. rer. nat. Department of Protein Science. Helmholtz Zentrum München.

1 E-mail: hauck@helmholtz-muenchen.de

2 E-mail: marius.ueffing@helmholtz-muenchen.de
} 
cos y también proteómicos para esta identificación. Con este fin, las células de Müller primaria, aisladas de la retina porcina, se cultivan durante periodos breves de tiempo in vitro, recogiendo las proteínas segregadas del medio de cultivo. Estas proteínas soportan la supervivencia de fotorreceptores en fotorreceptores primarios in vitro (5). También se demostró que promueven la aparición de células ganglionares retinales (6).

Las RMG segregan aproximadamente 1000 entidades proteínicas diferentes, pero la definición de los factores neuroprotectores activos dentro de ese grupo es como «buscar la aguja en el pajar». Gracias a técnicas proteómicas bien establecidas y al poder de la espectrometría de masa (EM), es posible separar a nivel bidimensional grandes grupos de proteínas diferentes utilizando el punto isoeléctrico de las mismas en una dimensión y el peso molecular en la segunda dimensión (fig. 1). Después de separar y teñir dichos geles de 2D, es posible extraer e identificar los puntos proteínicos de interés mediante la EM. Puesto que este método ha evolucionado muchísimo en los últimos 10 años, tanto en precisión como en sensibilidad, actualmente es posible identificar la mayoría de todas las proteínas segregadas que están inmersas en mezclas proteínicas tan complejas como en un medio condicionado a nivel celular. La estrategia para identificar los factores neurotróficos a utilizar consiste en aplicar métodos de fraccionamiento de proteínas nativas como la cromatografía líquida de intercambio de iones y combinarla con análisis sensible de cribado funcional e identificaciones de proteínas por espectrometría de masa de las subfracciones resultantes. Así podremos correlacionar sistemáticamente las actividades neurotróficas con proteínas aisladas especificas identificadas mediante la EM. Después de la clonación y expresión recombinante de las respectivas proteínas, podemos evaluar a nivel funcional cada candidato así como crear mezclas combinadas racionalmente de compuestos bioactivas para su actividad pro-supervivencia (5).

Considerando la intensa capacidad neuroprotectora de los factores derivados de las células de Müller, es probable que estas moléculas contengan un potencial enorme para aplicaciones terapéuticas: i) su expresión endógena en el interior de la retina como tejido diana promete menos efectos secundarios cuando se aplica terapéuticamente. ii) Debido a sus propiedades generalmente neuroprotectoras, estas moléculas pueden aplicarse para tratar formas hereditarias de DR sea cual fuere su defecto genético subyacente. La neuroprotección efectiva mediante factores neuroprotectores novedosos también depende del desarrollo de estrategias de entrega efectivas. Puesto que las proteínas no se difunden con la misma facilidad que otros compuestos más pequeños debido a su gran tamaño molecular, es crucial crear depósitos intraoculares que entre-

A

\section{primary RMG}

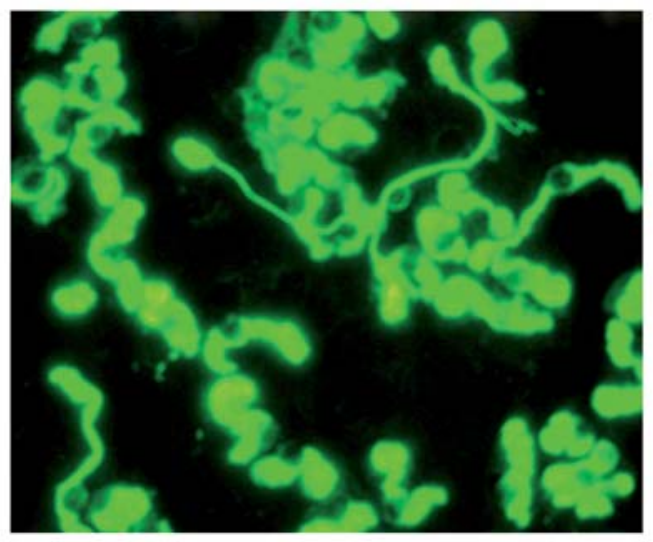

B

\section{acidic}
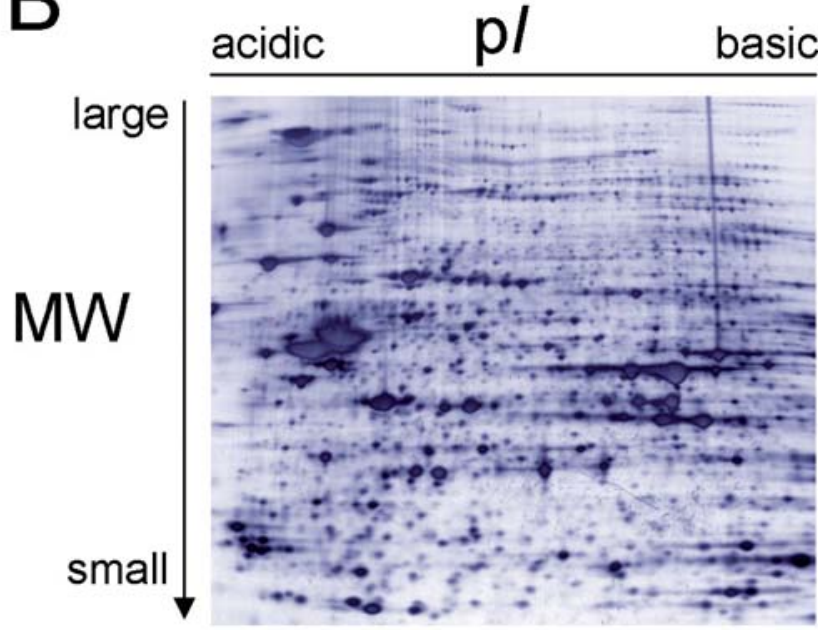

Fig. 1: A: Células retinales primarias de Müller marcadas con anticuerpo de anti-Glutaminsintetasa. B: Gel bidimensional de proteínas derivadas de células retinales primarias de Müller. Las proteínas se dividen según su punto isoeléctrico (pI) y luego se transfieren a geles de poliacrilamida de segunda dimensión, donde son separados por peso molecular $(M W)$. Después de la separación, las proteínas se visualizan tiñendo con azul de Coomassie. 
guen la proteína cerca de los fotorreceptores o células ganglionares afectadas. Estos depósitos deberían liberar la proteína terapéutica durante periodos largos de tiempo para evitar repeticiones de actos quirúrgicos invasivos. Por tanto, la terapia génica así como las estrategias de entrega basadas en células son necesarias para llevar nuevas moléculas a la retina de pacientes que esperan tratamientos para sus actualmente incurables enfermedades.

\section{BIBLIOGRAFÍA}

1. Frasson M, Picaud S, Leveillard T, Simonutti M, MohandSaid S, Dreyfus H, et al. Glial cell line-derived neurotrophic factor induces histologic and functional protection of rod photoreceptors in the $\mathrm{rd} / \mathrm{rd}$ mouse. Invest Ophthalmol Vis Sci 1999; 40: 2724-2734.
2. Hauck SM, Kinkl N, Deeg CA, Swiatek-de Lange M, Schoffmann S, Ueffing M. GDNF family ligands trigger indirect neuroprotective signaling in retinal glial cells. Mol Cell Biol 2006; 26: 2746-2757.

3. Bringmann A, Pannicke T, Grosche J, Francke M, Wiedemann P, Skatchkov SN, et al. Muller cells in the healthy and diseased retina. Prog Retin Eye Res 2006; 25: 397424.

4. Franze K, Grosche J, Skatchkov SN, Schinkinger S, Foja $C$, Schild D, et al. Muller cells are living optical fibers in the vertebrate retina. Proc Natl Acad Sci U S A 2007; 104: 8287-8292.

5. Hauck SM, Gloeckner CJ, Harley ME, Schoeffmann S, Boldt K, Ekstrom PA, et al. Identification of paracrine neuroprotective candidate proteins by a functional assaydriven proteomics approach. Mol Cell Proteomics 2008; 7: 1349-1361.

6. Garcia M, Forster V, Hicks D, Vecino E. Effects of muller glia on cell survival and neuritogenesis in adult porcine retina in vitro. Invest Ophthalmol Vis Sci 2002; 43: 37353743. 